\title{
Analysis on Hotel Management Strategy in Big Data
}

\author{
Xiaoli $\mathrm{Hu}$ \\ Sichuan Tianyi University, Mianzhu, Deyang, Sichuan, 610000
}

\begin{abstract}
With the deepening of the development of the Internet age and the work of profound changes in thinking, on all sectors of research institutions, management; down to the major forums, the media, language will be called data, language will talk about information, large data applications in the academic field set off A craze. Large data from the development of information technology and the Internet, and the proliferation of explosive ways to rapidly change our work and life, more and more areas began to focus on large data, and the use of large data as the promotion of industry restructuring and development The important opportunity, the tool and the way.
\end{abstract}

Keywords: Big Data, Hotel Management, Development Strategy

\section{Introduction}

Smart hotel attention and development based on the value of smart hotel, the value of information technology in hotel management in the integration and application. The heart of the hotel business is service, the core goal of the development of smart hotel is to improve service quality, enhance service value. The source of services based on demand, large data mining as a way of demand, natural wisdom in the development of the basic position of the hotel. From this dimension, the wisdom of hotel management is through data collection, collation and analysis, found unmet needs, in order to achieve the wisdom of hotel management and service delivery, improve hotel service efficiency and hotel management business model. 


\section{The Application of Big Data in Intelligent Hotel Management}

With the popularity of smart phones, more and more tourists choose to rely on intelligent APP to meet their travel needs to Ali, for example, through the Alipay for ticket booking, hotel occupancy, food buy and car rental generated a lot of data, This information through the data department of Ari finishing and analysis, not only can get the current trend of hotel selection, scientific forecasting, decision-making value; more can get personal data of tourism groups, hotel companies to provide accurate product development and management reference. Similarly, the consumption process in the residents of the reviews will also produce a lot of data, such data tend to fragmentation, but the highly targeted, after information extraction and semantic analysis, on the one hand, as a tourist guide, So that visitors to the purpose of a more comprehensive understanding of the hotel, on the other hand for the wisdom of the hotel to find user needs and hotel problems in the operation of the first-hand information provided in order to provide information management support for hotel management reform. This information than the information to be more real return visit.

In 2012, the National Tourism Administration issued a pilot plan for smart tourism, Beijing, Nanjing and other international cities have introduced the wisdom of the hotel industry standards and norms, the use of large data in the wisdom of the hotel gradually put on the agenda, which is mainly reflected in information sharing and resource integration Direction.

The use of large data is to promote the smart hotel marketing diversification, personalized, and improve the wisdom of hotel marketing targeted and timeliness, and enhance the wisdom of the hotel marketing appeal and influence. On the one hand, the hotel began to focus on optimizing the website marketing and promotion methods, and through Ctrip, where, eLong, the United States Mission and other travel sites cooperation in the tourism site registration information, become members to attract Web traffic browsing information, potential guests can clearly To understand the hotel's location, facilities, prices and service information, to achieve room reservation, to expand publicity and hotel visibility. However, this method also has its drawbacks, first, booking the company's high commissions prohibitive, the second information cluster, to stand out in the competitors is not easy. This prompted the hotel companies to actively seek the media, to expand distribution channels, some hotels self-built website, using search engines to promote, and some sites and well-known network marketing platform, such as life consulting platform and travel forums to attract the attention of guests. Of course, limited impact of marketing costs to maximize the case, or in the WeChat public platform, we can boldly predict, in the future, there will be more and more micro-hotel through the realization of the interaction and guests to show the potential customer information, To carry out promotional activities to achieve online and offline docking, breaking the traditional means of publicity, but also led to the hotel to pay the way of diversification. On the other hand, ant honeycomb and Ali travel and other vertical platform and the hotel industry more and more closely linked. Through the analysis of the user travel information sorting, you can analyze the user's itinerary and preferences, so as to 
recommend the destination for the user and reverse the hotel reservations. To ant honeycomb, for example, since the establishment of the data center, publishing user behavior data, there have been nearly 100 hotels and signed a cooperation agreement, of course, is expected to be more favorable Ali tourism, assuming that users A through Alipay purchased from Beijing to Hangzhou and three days after the return ticket, Ali travel through the data analysis, the user can push the threeday high-end hotel coupons; If the user travel many times, according to their travel options room and price range, The targeted delivery, the efficiency of natural marketing than the traditional high.

\section{Large data applications in the problems and difficulties}

The application of large data and wisdom Hotel development has made gratifying progress, but the wisdom of the hotel building process and the depth of the use of large data in the process there are still some problems and difficulties. Some travel agencies and hotel management agencies for the big data is still a lack of in-depth comprehensive understanding that the data is only an external manifestation of the Internet era, that the direction of building smart hotel should focus on high-end and intelligent, while ignoring the high-end The essence of personalization lies in the data mining and analysis, and the knowledge of large data is not deep enough. From the general situation, the domestic hotel for the construction of large data is lagging behind, there is no formation of resources to optimize the integration and linkage, so that the construction of intelligent hotels isolated from the data stream outside the industry. Of course, this aspect from the hotel executives for the ignorance of the data, more or because of the current data mining and finishing there is a certain degree of difficulty. Data storage and analysis requires a lot of capital investment and equipment support, so that the traditional line of hotel powerless, only through large-scale platform with the Internet companies to cooperate to achieve data management, which is not conducive to intelligent hotel data ownership Into, not to mention the initiative to carry out the analysis of the data.

\section{Business Strategy of Single Hotel in Big Data}

Establish the strategic concept of data management. Driven by large data technology, intelligent micro-booking, mobile marketing, CRM database will become the main direction of the development of the industry, individual hotels to follow the main trend of the times, establish data, technology and philosophy of the Trinity of the new data management thinking. In addition, it is technical problems, but also the key lies in the hotel manager's ideas and ideas.

Improve data docking, the establishment of self-media marketing platform. The so-called data docking, popular that is the hotel's own menu, room status, prices and other product sales dynamic data uploaded to the first time product 
distribution channels, and automatically access the distribution channels of the order, the hotel also has a single consumer Including a number of sales channels.

The current domestic monomer hotel product sales mainly through the OTA platform, especially the WeChat public platform was born, marking the audiencedriven since the media network 3.0 era, the establishment of the hotel from the media marketing platform micro booking, is currently the domestic monomer Hotels highlight the important way the market tight encirclement and high ground,

In the era of large data, single hotel to really realize the commission, we must establish a media marketing data platform, through effective data mining for high-quality analysis and forecasting, precise positioning of the source market and accurate marketing strategy, and through good The use of instant media from the media and interactive features of data dissemination, and strive to expand the hotel "micro-booking \# market influence, and gradually get rid of the intermediary booking platform profit squeeze, the initiative to grasp the hotel product marketing .

The formation of regional monomer hotel new alliance, the implementation of large chain development, with the domestic hotel chain branding, and various forms of hotel Union, the strength of thin single hotel with its brutal competition was forced out, it is better to unite, Baotuan take warm, explore new development outlet, and joined the well-known brand hotel chain because of its high initial fee. Own brand disappears. A variety of brand fees and upgrades and other expenses, making a lot of single hotels were shut out.

However, chain operation is an inevitable trend of the future development of single hotel, so monomer hotel must explore a form of chain, the formation of regional body hotel alliance, take the road of development of large chain, the regional monomer hotel alliance is the While maintaining its own operating characteristics, the single hotel will use the Internet and large data technology to form a new type of hotel consortium that is jointly developed and shared by large chain stores to realize the optimization of management mode and the improvement of service quality. Standardization and network management, single hotel through this management mode of creative replication, both to maintain its own brand, while taking full advantage of the regional monomer hotel alliance brand management strategy to promote the growth of its own brand .

Hotel industry to raise awareness, on the one hand actively into smart room construction. Smart room is to collect user data and the source of demand, only to achieve the wisdom of the room in order to ensure the authenticity of data collection; the other hand, to actively carry out online hotel booking platform, the construction of smart hotel is not isolated, Line of data is the database, online data is the basic characteristics. Only in this way can we realize the information integration of the hotel's internal system and the resource sharing outside the hotel, realize the docking of the intelligent hotel and the city's intelligent tourism, and realize the information-oriented and service-oriented transformation of the hotel industry.

Hotel research institutions are to actively carry out the hotel information system development. With the experience and advantages of online travel platform, the establishment of a relatively independent information collection 
platform, focusing on the collection of customer information, to establish a relatively complete database of customer information, of course, this is not an overnight job, but the benefits will be far away. The system must be open, if the closure would not make any sense. Our biggest problem is not without information collection system, nor is the lack of technical means, but the industry information sharing mechanism is not caused by the formation of the statistical data is not scientific, and not a good guide to the wisdom of hotel management, can not meet the wisdom of hotel data Of the requirements.

\section{Conclusion}

The advent of the era of large data is the development of the hotel industry transformation opportunities, but also for the construction of the wisdom of the hotel made a series of new problems, the use of large data will fundamentally change the current status of hotel management, the birth of a new model of hotel management, And all this will take place in our efforts.

\section{References}

[1] Cheng Shanlan. Borrow large-scale data to boost the wisdom of Suzhou hotel development [J]. Business Economics, 12(4), pp. 132-138, 2014.

[2] Zhong Yan, Gao Jianfei. The Research on the Information Construction of Domestic Hotel Group [J]. Business Times, 35(2), pp. 10-21, 2013.

[3] Zhang Yin, Chen Min, Liao Xiao-fei.The Present Situation and Prospect of Large Data Application [J] .Journal of Computer Research and Development. , 7(2), pp. 39-46, 2009.

[4] Meng Xiaofeng, Large Data Management: Concept, Technology and Challenges [J] .Journal of Computer Research and Development, 6(2), pp. 17-21, 2011.

[5] Wang Ling. On China's hotel industry information system application status and development prospects [J]. Herald, 5(2), pp. 20-25, 2013. 